\title{
Molecular detection, phylogenetic and evolutionary analysis of porcine bocavirus in central China
}

\author{
Lan-Lan Zheng ${ }^{1}$, Jian-Tao Cui ${ }^{1}$, Han Qiao ${ }^{1}$, Xin-Sheng Li $^{1}$, Xiaokang Li $^{1}$, and Hongying \\ Chen $^{1}$ \\ ${ }^{1}$ Affiliation not available
}

July 7,2020

\begin{abstract}
To investigate the phylogenetic and evolutionary analysis of porcine bocavirus (PBoV), 281 clinical samples including 236 intestinal tissue samples and 45 fecal samples were collected from diarrheal piglets in 27 different pig farms of central China, and SYBR Green I-based qPCR assays were developed to detect PBoVs. Among the 281 samples, 148 (52.67\%) were positive for PBoV1/2, 117 (41.63\%) were positive for PBoV3/4/5, and 55 (19.57\%) were positive for both PBoV1/2 and PBoV3/4/5. Subsequently, two complete genome sequences of PBoV strains CH/HNZM (accession numbers KX017193) and PBoV-TY (accession numbers MH454686) were cloned in this study. A multiple genomic sequence alignment showed that the pairwise similarity of the two PBoV strains was $94.8 \%$, and they had $44.5 \%-95.8 \%$ genomic nucleotide sequence identity with 35 reference strains. The phylogenetic analysis demonstrated that the two PBoV strains CH/HNZM and PBoV-TY clustered into the PBoV2 group, and PBoV-TY was closely related to the PBoV strain GD18 strain (KJ755666) which may be derived from PBoV strains 0912/2012 (MH558677) and 57AT-HU (KF206160) through the recombination analysis. Compared with reference strain ZJD (HM053694)-China, a higher variation in the NS1 amino acids of PBoVs was found for CH/HNZM and PBoV-TY. These results had provided further information of the $\mathrm{PBoV}$ prevalence in central China, and they extend our understanding of the molecular epidemiology and evolution of PBoV.
\end{abstract}

\section{INTRODUCTION}

Bocavirus is a novel classified genus which belongs to the family Parvoviridae, subfamily Parvovirinae , and includes human bocavirus $(\mathrm{HBoV})$, porcine bocavirus $(\mathrm{PBoV})$, canine minute virus $(\mathrm{CMV})$, bovine bocavirus (BPV), gorillas bocavirus (GBoV), and California sea lion bocavirus (CslBoV) (Lau et al., 2008; Li et al., 2011). In 2009, porcine boca-like virus (PBo-likeV) was first reported from lymph nodes of pigs with post-weaning multi-systemic wasting syndrome (PMWS) in Sweden (Blomstrom et al., 2009). PBo-likeV was subsequently discovered in China and named as porcine bocavirus (PBoV) or PBoV1 in 2010 (Zhai et al., 2010). Since then, PBoV has been identified in Europe, Asia, North America and Africa (Zhou et al., 2014).

$\mathrm{PBoV}$ is a non-enveloped single-stranded DNA virus which consists of three open reading frames (ORFs), ORF1, ORF2, and ORF3 (Arthur et al., 2009). ORF1 encodes a nonstructural protein 1 (NS1), ORF2 encodes viral caspid proteins 1 and 2 ( VP1/2), and VP1 consists of the entire VP2 sequence and an additional N-terminal region (Sun et al., 2009), ORF3 encodes nuclear phosphoprotein 1(NP1 ). Based on the $V P 1$ and $V P 2$ sequences, $\mathrm{PBoV}$ has been classified into different clades, which includes PBoV1, $\mathrm{PBoV} 2$, $\mathrm{PBoV} 3, \mathrm{PBoV} 4, \mathrm{PBoV} 5, \mathrm{PBoV} 3 \mathrm{C}, \mathrm{PBoV}-6 \mathrm{~V}$ and $\mathrm{PBoV}-7 \mathrm{~V}$. And $\mathrm{PBoV}$ was proposed to be classified into three different groups, PBoV G1, PBoV G2, and PBoV G3 (Zhou et al., 2014).

To date, pigs infected with PBoV have been reported in 20 provinces or regions in China with the prevalence between 7.3\% and 64\% (Wang et al., 2014; Zhang et al., 2015; Zhou et al., 2018). Co-infection of PBoV 
with other porcine viruses has also been reported, such as porcine epidemic diarrhea virus (PEDV), porcine circovirus type 2 (PCV2), pseudorabies virus (PRV), porcine reproductive and respiratory syndrome virus (PRRSV), porcine torque teno virus (PTTV) and classic swine fever virus (CSFV) (Blomstrom et al., 2010; McMenamy et al., 2013; Zhang et al., 2014; Huang et al., 2014; Zhou et al., 2014; Luo et al., 2015). In addition, PBoV has a significantly higher infection rate in diseased pigs than in healthy pigs, and the coinfection rate of PEDV and $\mathrm{PBoV}$ was higher in samples of diarrheal pigs than that of healthy pigs, suggesting that the PBoV might play an important role in causing diarrhea in piglets (Zhai et al., 2010). However, the pathogenicity of $\mathrm{PBoV}$ needs further recognized. In the current study, we aimed to investigate the PBoV prevalence in diarrheal pigs and analyze full-length genome sequence properties of $\mathrm{PBoV}$ from central China.

\section{MATERIALS AND METHODS}

\subsection{Sample collection and DNA preparation}

From 2016 to 2019, a total of 281 samples including 236 intestinal tissue samples and 45 fecal samples were collected from diarrheal piglets in 27 different pig farms in 18 cities of central China. Samples were diluted 1:10 with phosphate-buffered saline (PBS, pH7.4), and the suspensions were vortexed and centrifuged at $12000 \times \mathrm{g}$ for $5 \mathrm{~min}$ at $4^{\circ} \mathrm{C}$ to collect the clarified supernatants. The viral DNA was extracted using an UNlQ-10 Column Virus Genomic DNA Isolation Kit (Sangon Biotech Shanghai Co, Ltd., China) according to the manufacturer's instructions. The concentration of DNA was calculated and stored at $-80^{\circ} \mathrm{C}$.

\subsection{Primers design}

Eighteen genome nucleotide sequences of PBoVs were downloaded from the GenBank and subjected to perform homology analysis using the MegAlign program of DNAStar software (version 7.1, DNASTAR Inc., Madison, USA). The highly conserved sequences within the NS1 gene were determined from an alignment of nine PBoV1/2 genomic sequences (GenBank accession number HM053693, HM053694, HQ291309, KF025392, KF025393, KF206155, KF206157, KF206161 and KM402139), and a pair of primers PBoV1/2F/R was designed using the Primer Premier (version 6.0, USA) software based on the sequence of GenBank accession number HM053693, which gave an amplification product of 327 bp (Table 1). The specific primers for $\mathrm{PBoV} 3 / 4 / 5$ were found from an alignment of nine sequences of PBoV3/4/5 (GenBank accession number JF429834, JF713714, KC473563, JF713715, JN681175, JF429836, KF206158, JN621325 and JN831651), and a pair of primers $\mathrm{PBoV} 3 / 4 / 5-\mathrm{F} / \mathrm{R}$ targeting the $V P 1$ gene of $\mathrm{PBoV} 3 / 4 / 5$ was designed based on the sequence of GenBank accession number JF429834, amplifying a fragment of $209 \mathrm{bp}$ (Table 1). In addition, three pairs of specific PCR primers (Q1F/Q1R, Q2F/Q2R and Q3F/Q3R) were designed according to the reference sequence (GenBank accession number HM053693) to amplify three overlapping fragments covering the entire viral genome (Table.1).

\subsection{Development of SYBR GreenIbased real-time PCR assays}

To develop the SYBR Green I-based real-time PCR assays for detection of PBoV1/2 and PBoV3/4/5, the standard curves were generated. Conventional PCR amplifications with primers PBoV1/2-F/R and PBoV3/4/5-F/R were performed using the PCT-200 Peltier thermal cycler (MJ Research, USA). The positive PCR products were purified using the Gel Extraction Mini Kit (Watson Biotechnologies. INC) according to the manufacturer's instructions, and cloned into pMD18-T vector (Takara, Dalian, China). The recombinant plasmids were designed as pMD18-327 and pMD18-209 respectively, and then transformed into Escherichia coli DH-5 $\alpha$ competent cells (TaKaRa). Positive clones were isolated and submitted for sequencing. The concentrations and purities of the two standard plasmids were quantified by ultraviolet absorbance at 260 $\mathrm{nm}$ and $280 \mathrm{~nm}$ using a Nano-100 micro-spectrophotometer (Thermo Fisher Scientific, Waltham, MA, USA). The copy numbers of plasmids were determined and 10 -fold serial diluted in TE buffer $(10 \mathrm{mM}$ Tris- $\mathrm{HCl}$, $1 \mathrm{mM}$ EDTA). The real-time PCR standard curves for detection of PBoV1/2 and PBoV3/4/5 were generated with a known copy number (from $1 \times 10^{9}$ to $1 \times 10^{0}$ copies/ $\mu \mathrm{L}$ ) of the recombinant plasmids pMD18-327 and pMD18-209, and performed in triplicate, respectively. The parameters of the SYBR Green I-based real-time PCR reactions were optimized, and the sensitivity, specificity and reproducibility were evaluated. 
The SYBR Green I-based real-time PCR amplifications of PBoV1/2 and PBoV3/4/5 were performed using the Rotor Gene 2000 real-time thermal cycler (Corbett Research, Australia). PCR was performed in a 20 $\mu \mathrm{L}$ volume containing $3 \mu \mathrm{L}$ DNA of samples, $10 \mu \mathrm{L}$ of $2 \times$ SYBR Premix Ex Taq I, $0.5 \mu \mathrm{L}(25 \mu \mathrm{mol} / \mathrm{L})$ of each primer and $6 \mu \mathrm{L}$ distilled water. The amplification conditions were $95^{\circ} \mathrm{C}$ for $3 \mathrm{~min}$ as initial denaturation followed by 39 cycles of $95^{\circ} \mathrm{C}$ for $30 \mathrm{~s}, 58^{\circ} \mathrm{C}$ for $25 \mathrm{~s}$ and $72^{\circ} \mathrm{C}$ for $30 \mathrm{~s}$.

\subsection{Complete genome sequence amplification}

For the two primer sets (Q1F/Q1R and Q2F/Q2R), PCR protocol was carried out in $25 \mu \mathrm{L}$ of the reaction mixture: $12.5 \mu \mathrm{L}$ of 2 Phanta Max Buffer, $2 \mu \mathrm{L}$ of sample DNA, $1 \mu \mathrm{L}$ of Phanta Max Super, $0.5 \mu \mathrm{L}$ of dNTP Mix, $0.5 \mu \mathrm{L}$ of each primer $(50 \mu \mathrm{M})$, and $8 \mu \mathrm{L}$ of $\mathrm{ddH}_{2} \mathrm{O}$. The PCR parameters were as follows: pre-denaturation at $94^{\circ} \mathrm{C}$ for $3 \mathrm{~min}$; followed by 35 cycles of denaturation at $98^{\circ} \mathrm{C}$ for $10 \mathrm{~s}$, annealing at $55^{\circ} \mathrm{C}$ for $15 \mathrm{~s}$, extension at $72^{\circ} \mathrm{C}$ for $2 \mathrm{~min}$, and then followed by a final extension step at $72^{\circ} \mathrm{C}$ for $10 \mathrm{~min}$. For the Q3F/Q3R primer sets, PCR protocol was carried out in $25 \mu \mathrm{L}$ of the reaction mixture: $12.5 \mu \mathrm{L}$ of 2Es Taq Master Mix (Dye), $3 \mu \mathrm{L}$ of sample DNA, $0.5 \mu \mathrm{L}$ of each primer $(50 \mu \mathrm{M})$, and $8.5 \mu \mathrm{L}$ of $\mathrm{dd}_{2} \mathrm{O}$. The PCR parameters were as follows: pre-denaturation at $95^{\circ} \mathrm{C}$ for $5 \mathrm{~min}$; followed by 35 cycles of denaturation at $95^{\circ} \mathrm{C}$ for $45 \mathrm{~s}$, annealing at $60^{\circ} \mathrm{C}$ for $45 \mathrm{~s}$, extension at $72^{\circ} \mathrm{C}$ for $2 \mathrm{~min}$, and then followed by a final extension step at $72^{\circ} \mathrm{C}$ for $10 \mathrm{~min}$. The purified products were cloned into the pMD18-T Vector (TaKaRa) for sequencing, and all sequencing reactions were performed in duplicate.

\subsection{Sequence alignment and phylogenetic analyses}

Genomic sequences of two PBoV strains obtained in this study were screened for sequence similarities using BLAST (http://www.ncbi.nlm.nig.gov/BLAST) against the database in GenBank. The genomic sequences of two PBoV strains and 35 reference strains (Table 2) were aligned and analyzed using the MegAlign program of the DNAstar software (version 7.1, DNASTAR Inc., USA). Phylogenetic analysis was performed using the minimum-evolution method in the Molecular Evolutionary Genetics Analysis (MEGA) software (version 6.0) with Kimura distances, and a bootstrap of 1,000 replicates.

Seven recombination detection methods (RDP, GENECONV, BOOTSCAN, MaxChi, Chimaera, SiScan and 3Seq) embedded in Recombination detection program (RDP 4.39) were used to detected recombinant events in the two complete genomes of $\mathrm{PBoV}$. Only those recombination events supported by more than four programs were deemed to avoid dependence on a single detection method as described previously (Zhai et al., 2010), and the window size was set to $20 \mathrm{bp}$, the highest acceptable $\mathrm{P}$ value was 0.01 .

\section{RESULTS AND DISCUSSION}

SYBR Green I-based qPCR assays were developed to detect PBoV1/2 and PBoV3/4/5 in clinical samples from diarrheal piglets in 18 cities of central China. The standard curve of PBoV1/2 was y $=-3.6726 \mathrm{x}$ +41.425 , with $\mathrm{R}^{2}$ values (square of the correlation coefficient) of 0.99 , and the detection limit was 16.6 copies $/ \mu \mathrm{L}$. The standard curve of $\mathrm{PBoV} 3 / 4 / 5$ was determined to be $\mathrm{y}=-3.3379 \mathrm{x}+39.137$, with $\mathrm{R}^{2}$ values of 0.99 , and the minimum detection limit was 33 copies/ $\mu \mathrm{L}$. For the evaluation of specificity, PBoV1/2 was detected with a specific melting peak that the melting temperatures $(\mathrm{Tm})$ was $88^{\circ} \mathrm{C}$ and $\mathrm{PBoV} 3 / 4 / 5$ with the Tm of $85^{\circ} \mathrm{C}$. However, transmissible gastroenteritis virus (TGEV), PEDV, PRRSV and PRV had no melting peaks. The reproducibility of the assays was determined in triplicate using inter- and intra-assay comparisons. The values of the intra-assay standard deviation (SD) and co-efficient of variation (CV) ranged from 0.010 to 0.042 and $0.076 \%$ to $0.678 \%$, respectively. The values of the inter-assay SD and CV ranged from 0.112 to 0.539 and $0.768 \%$ to $2.304 \%$, respectively. These results showed that the SYBR Green I-based qPCR assays for PBoV1/2 and PBoV3/4/5 detection were really good to use with highly sensitive, specific, and reproducibility.

According to the SYBR Green I-based PCR detection results of 281 clinical samples, 148 samples (148/281, $52.67 \%)$ were positive for PBoV1/2, 117 samples $(117 / 281,41.63 \%)$ were positive for $\mathrm{PBoV} 3 / 4 / 5$, and 55 samples $(55 / 281,19.57 \%$ ) were positive for both PBoV1/2 and PBoV3/4/5. Overall, the prevalence of PBoV was $74.73 \%$ in central China $(210 / 281$ ), and it was much higher than that of previous reports (Zhang et 
al. 2015; Zhou et al. 2018b) in China which showed that PBoV mainly distributed in the east and south coastal areas of China, and Jiangsu province was the center of high PBoV occurrence frequency. However, our results suggested that $\mathrm{PBoV}$ has broadly distributed among swine farms in diarrheal piglets in central China, indicating that this virus should be thought as a probable cause of diarrhea in pigs.

In this study, PEDV and PCV2 were also detected. The infection rate of PEDV was $76.87 \%(216 / 281)$, and the co-infection rate of $\mathrm{PBoV}$ and PEDV was $49.11 \%$ (138/281). PCV2 was found in all the positive samples of $\mathrm{PBoV}$. The high co-infection rate of PCV2 and $\mathrm{PBoV}$ in this study demonstrated that the higher PBoV prevalence in samples from pigs with PWMS, which were similar to results reported previously (Blomstrom et al., 2010), suggested that PBoV might play a role in the development of PMWS. In addition, the co-infection of PBoV with other pathogens was common, such as PRRSV, CSFV (Blomstrom et al., 2010; Meng, 2012; McMenamy et al., 2013; Luo et al., 2015). Pfankuche et al. (Pfankuche et al., 2016) reported that PBoV should be considered as a pathogen that triggers encephalomyelitis. Zhang et al. (Zhang et al., 2015) found a higher incidence of $\mathrm{PBoV}$ in diarrheic pigs (73.95\%) when compared with healthy pigs (47.83\%). However, until now, there has no definite clinical disease associated to PBoV.

Two complete genomes of PBoV strains (CH/HNZM and PBoV-TY) were acquired and then the alignment analyses showed that they also had three putative ORFs. The genomic length of PBoV strain $\mathrm{CH} / \mathrm{HNZM}$ was $5173 \mathrm{nt}$, encoding NS1 (2,112 nt), VP1 and VP2 (2,115 nt, including 1,701 nt VP2 ) and NP1 (687 nt), respectively. The PBoV strain PBoV-TY comprised 5156 nt in length, with 2,112 nt NS1 gene, 2118 nt VP1 /VP2 gene (1,704 nt VP2 ), and 690 nt NP1 gene. The genetic relationships of two PBoV strains with 35 reference strains (Table 2) were analyzed by constructing the phylogenetic tree based on genomic nucleotide sequences. The results showed that the pairwise similarity of the two PBoV strains was $94.8 \%$, and these representative $\mathrm{PBoV}$ strains could be divided into three clusters, $\mathrm{PBoV} 1, \mathrm{PBoV} 2$ and $\mathrm{PBoV} 3 / 4 / 5$. The two $\mathrm{PBoV}$ strains $\mathrm{CH} / \mathrm{HNZM}$ and $\mathrm{PBoV}-\mathrm{TY}$ were clustered into the PBoV2 group, formed a large branch with other 12 PBoV2 strains, and had 86.8\%-95.8\% nucleotide sequence homology. However, they were phylogenetically distinct from PBoV1, PBoV3/4/5 or HBoV groups (44.5\%-55.3\%) (Fig.1). Interestingly, PBoV3/4/5 group showed a closer phylogenetic relationship with $\mathrm{HBoV}$ than that with PBoV1 or PBoV2 groups, which indicated that $\mathrm{PBoV} 3 / 4 / 5$ group might be a further source of $\mathrm{HBoV}$. Additionally, the phylogenetic trees based on the amino acid sequences of $N S 1, N P 1, V P 1$ and $V P 2$ proteins for all 37 bocaviruses were constructed. The results showed that PBoV1 and PBoV2 strains were closer based on NS1 analysis (Fig.S1) and were placed in a large cluster altogether with CslBoV1 and CMV strains, whilst PBoV3/4/5 strains were in an independent branch. PBoV1 and PBoV2 strains were in a large cluster based on the NP1 sequences (Fig.S2), whilst PBoV3/4/5 strains were situated in another branch with 7 other bocaviruses. Based on their VP1 and VP2 amino acid sequences (Fig.S3, S4), PBoV1 and PBoV2 formed a large cluster altogether with CslBoV1 and CMV strains, whilst PBoV3/4/5 was in a large cluster altogether with $\mathrm{HBoV}$ and BPV1. On the basis of the phylogenetic tree analysis of the NS1, NP1, VP1 and VP2 protein sequences, the two PBoV strains $\mathrm{CH} / \mathrm{HNZM}$ and $\mathrm{PBoV}$-TY belonged to $\mathrm{PBoV} 2$, which was identical to the result of phylogenetic tree analysis of the genomic nucleotide sequences. Moreover, some PBoV strains are closely related to HBoVs, leading to the hypothesis that HBoV could be of zoonotic origin (Malecki et al., 2011; Zhang et al., 2013). Thus, it is vital to pay more attention to the emerging and reemerging PBoVs of swine.

Capsid proteins of parvoviruses have close relationship with immunogenicity and tissue tropism. Minor genetic changes of proteins could alter the pathogenic potential and host range of parvoviruses (Kapoor et al., 2012). In this study, the amino acids of $N S 1, V P 1, V P 2$ and $N P 1$ of the PBoV strains were compared and analyzed. Among the $28 \mathrm{PBoV}$ reference strains we listed in this study, PBoV strain ZJD (HM053694)-China is a nearly full-length genome sequence with $5186 \mathrm{nt}$ that identified for the first time in porcine samples in China in 2010 (Cheng et al., 2010). We chose this strain as the comparison, and the amino acids of NS 1, VP1, VP2 and NP1 of the two PBoV strains were compared with the reference strain ZJD (HM053694)-China.

ORF1 that encoding NS 1 is located at the 5' end of the PBoV genome, and is essential for DNA replication. It has been illustrated to contain conserved motifs associated with rolling-circle replication, helicase and ATPase activities (Lau et al., 2011). After compared the NS 1 amino acids of the two PBoV strains with the 
reference strain ZJD (HM053694)-China, PBoV strain CH/HNZM contained eight major aa variation sites, and $\mathrm{PBoV}$ strain $\mathrm{PBoV}-\mathrm{TY}$ contained four aa variation sites. There were six aa variation sites between the two PBoV strains CH/HNZM and PBoV-TY (Table.S1). Moreover, a higher variation in the NS 1 amino acids of $\mathrm{PBoVs}$ was found in this study, which was inconsistent with $\mathrm{PBoV}$ strains from pigs in the USA (Jiang et al., 2014). ORF2 codes the capsid proteins VP1 and VP2 , and a conserved "YXGXF" motif domain was in the unique VP1 protein $(V P 1 \mathrm{u}$ ) (Yang et al., 2012). This domain indicates a secretory phospholipase A2 (sPLA2) activity that is critical for parvovirus infectivity (Cheng et al., 2010). On the basis of VP1 and VP2 amino acids of the two PBoV strains and comparison with reference strain ZJD (HM053694)-China, $\mathrm{PBoV}$ strain $\mathrm{CH} / \mathrm{HNZM}$ contained three major aa variation sites, and PBoV strain PBoV-TY contained two aa variation sites in $V P 1$. PBoV strain $\mathrm{CH} / \mathrm{HNZM}$ contained four major aa variation sites, and $\mathrm{PBoV}$ strain $\mathrm{PBoV}$-TY contained three aa variation sites in $V P 2$. There were only one aa variation site between the two PBoV strains (CH/HNZM and PBoV-TY) both in VP 1 and VP 2 amino acids (Table.S1). ORF3 encodes the NP1 protein that is located between ORF1 and ORF2, which is a characteristic genetic feature of the Bocavirus genus. Although the function of NP1 in PBoV remains unclear, it is essential for CMV DNA replication (Sun et al., 2009). There were four aa variation sites when comparison with reference strain ZJD (HM053694)-China, and two aa variation sites were found between PBoV strains CH/HNZM and PBoV-TY (Table.S1).

The accumulation of point mutations is an important mechanism for the evolution of the Parvovirinae, and recombination could increase the generation of new genotypes of $\mathrm{PBoVs}$, which improve their capacity to adapt and spread among Suidae hosts worldwide (Lau et al., 2011; Zeng et al., 2011). The recombination analysis revealed that one putatively recombinant breakpoint was existed in GD18 (KJ755666) strain located in the VP1/2 gene at position 3,458 to 4,986 nt of the genome (Fig.2). The major parent strain was 0912/2012 (MH558677) and the minor parent strain was 57AT-HU (KF206160), which were supported by 7 programs (RDP, Av. P-Val $=3.158 \times 10^{-14}$; GENECONV, Av. P-Val $=5.595 \times 10^{-10}$; BOOTSCAN, Av. P-Val $=$ $3.85 \times 10^{-14}$; MaxChi, Av. P-Val $=1.89 \times 10^{-12}$; Chimaera, Av. P-Val $=1.988 \times 10^{-13}$; SiScan, Av. P$\left.\mathrm{Val}=9.891 \times 10^{-19} ; 3 \mathrm{Seq}, \mathrm{Av} . \mathrm{P}-\mathrm{Val}=8.082 \times 10^{-14}\right)$. Although no recombination signal was found for either PBoV strain $\mathrm{CH} / \mathrm{HNZM}$ or PBoV-TY with other PBoVs, the PBoV strain PBoV-TY was clustered in a small branch altogether with PBoV strain GD18 from Guangdong province of China in 2013, with 94.2\% genomic nucleotide identity. The results demonstrated that PBoV strain $\mathrm{CH} / \mathrm{HNZM}$ or PBoV-TY may be novel members of the genus bocavirus. Besides, a high prevalence of mixed infection with PBoV1/2 and $\mathrm{PBoV} 3 / 4 / 5$ was reported, which provided the possibility of recombination in the future.

In conclusion, this is the first study to demonstrate the prevalence of $\mathrm{PBoV}$ in pig farms in central China. Two complete genome sequences of PBoV2 field strains were characterized, phylogenetic and recombination analyses were conducted. The present study indicates that PBoVs are prevalent in central China, and the co-infection with PEDV or PCV2 is very common. The results of this study provide valuable information for the further analysis of epidemiology and biological characteristics of PBoV.

\section{Nucleotide sequence accession numbers}

The two complete genome sequences of PBoV strains CH/HNZM and PBoV-TY have been submitted to the GenBank, and accession numbers are KX017193 and MH454686, respectively.

\section{ACKNOWLEDGEMENTS}

This work was supported by the National Natural Science Foundation of China [grant number 31802218]; Young Teacher Foundation of Henan Province [grant number 2019GGJS051]; Zhongyuan high level talents special support plan [grant number 204200510015] and Henan Agricultural University Technology Innovation Fund [grant number KJCX2018C02].

\section{CONFLICT OF INTEREST}

The authors declare that they have no conflict of interest.

\section{DATA AVAILABILITY STATEMENT}


The data that support the findings of this study are openly available in this manuscript and the Supporting Information attached.

\section{References}

Arthur, J. L., Higgins, G. D., Davidson, G. P., Givney, R. C., \& Ratcliff, R. M. (2009). A novel bocavirus associated with acute gastroenteritis in Australian children. PLoS pathogens, 5, e1000391. https://10.1371/journal.ppat.1000391

Blomstrom, A. L., Belak, S., Fossum, C., McKillen, J., Allan, G., Wallgren, P., \& Berg, M., (2009). Detection of a novel porcine boca-like virus in the background of porcine circovirus type 2 induced postweaning multisystemic wasting syndrome. Virus Research, 146, 125-129. https://10.1016/j.virusres.2009.09.006

Blomstrom, A. L., Belák, S., Fossum, C., Fuxler, L., Wallgren, P., \& Berg M. (2010). Studies of porcine circovirus type 2, porcine boca-like virus and torque teno virus indicate the presence of multiple viral infections in postweaning multisystemic wasting syndrome pigs. Virus research, 152, 59-64. https://10.1016/j.virusres.2010.06.004

Cheng, W. X., Li, J. S., Huang, C. P., Yao, D. P., Liu, N., Cui, S. X., .. Duan, Z. J. (2010). Identification and nearly full-length genome characterization of novel porcine bocaviruses. PLoS One, 5, e13583. https://10.1371/journal.pone.0013583

Gunn, L., Collins, P. J., Fanning, S., McKillen, J., Morgan, J., Staines, A., \& O'Shea, H. (2015). Detection and characterisation of novel bocavirus (genus Bocaparvovirus) and gastroenteritis viruses from asymptomatic pigs in Ireland. Infection ecology \& epidemiology, 5, 27270. https://10.3402/iee.v5.27270

Jiang, Y. H., Xiao,C. T., In, S. H., Gerber, P. F., Halbur, P. G. \& Opriessnig, T. (2014). High prevalence and genetic diversity of porcine bocaviruses in pigs in the USA, and identification of multiple novel porcine bocaviruses, Journal of general virology, 95, 453-465. https://10.1099/vir.0.057042-0

Huang, J., Mor, S. K., Erber, J., Voss, E., \& Goyal, S. M. (2014). Detection and characterization of porcine bocavirus in the United States. Archives of virology, 159, 1797-1801. https://10.1007/s00705-013-1972-4

Lau, S.K., Woo, P.C., Tse, H., Fu, C.T., Au, W.K., Chen, X.C., ... Yuen, K.Y. (2008), Identification of novel porcine and bovine parvoviruses closely related to human parvovirus 4. Journal of general virology, 89, 1840-1848. https://10.1099/vir.0.2008/000380-0

Lau, S. K., Woo, P. C., Yip, C. C., Li, K. S.; Fu, C. T., Huang, Y., .. Yuen, K. Y. (2011). Co-existence of multiple strains of two novel porcine bocaviruses in the same pig, a previously undescribed phenomenon in members of the family Parvoviridae, and evidence for inter- and intra-host genetic diversity and recombination. Journal of general virology, 92, 2047-2059. https://10.1099/vir.0.033688-0

Li, L., Shan, T., Wang, C., Cote, C., Kolman, J., Onions, D., .. Delwart, E., (2011). The fecal viral flora of California sea lions. Journal of virology, 85, 9909-9917. https://10.1128/JVI.05026-11

Li, R., Qiao, S., Yang, Y., Guo, J., \& Zhang, G. (2016). Genome sequencing and analysis of a novel recombinant porcine epidemic diarrhea virus strain from Henan, China. Virus Genes, 52:91-98. https://10.1007/s11262-015-1254-1

Luo, Y., Liang, L., Zhou, L., Zhao, K., \& Cui, S. (2015). Concurrent infections of pseudorabies virus and porcine bocavirus in China detected by duplex nanoPCR. Journal of virological methods, 219, 46-50. https://10.1016/j.jviromet.2015.03.016

Kapoor, A., Mehta, N., Dubovi, E. J., Simmonds, P., Govindasamy, L., Medina, J. L., ... Lipkin, W. I. (2012). Characterization of novel canine bocaviruses and their association with respiratory disease. Journal of general virology, 93, 341-346. https://10.1099/vir.0.036624-0

Malecki, M., Schildgen, V., \& Schildgen, O. (2011). Human bocavirus: still more questions than answers. Future Virology, 6:1107-1114. https://10.2217/fvl.11.78 
McMenamy, M. J., McKillen, J., McNair, I., Duffy, C., Blomstrom, A. L., Charreyre, C., ... Allan, G. (2013). Detection of a porcine boca-like virus in combination with porcine circovirus type 2 genotypes and Torque teno sus virus in pigs from postweaning multisystemic wasting syndrome (PMWS)-affected and non-PMWS-affected farms in archival samples from Great Britain. Veterinary microbiology, 164, 293-298. https://10.1016/j.vetmic.2013.03.009

Meng, X. J. (2012). Emerging and re-emerging swine viruses. Transboundary and emerging diseases. Transboundary and Emerging Diseases, 59, Suppl 1, 85-102. https://10.1111/j.1865-1682.2011.01291.x

Pfankuche, V. M., Bodewes, R., Hahn, K., Puff, C., Beineke, A., Habierski, A., .. Baumgartner, W. (2016). Porcine Bocavirus Infection Associated with Encephalomyelitis in a Pig, Germany(1). Emerging infectious diseases, 22, 1310-1312. https://10.3201/eid2207.152049

Sun, Y., Chen, A. Y., Cheng, F., Guan, W., Johnson, F. B., \& Qiu, J. (2009). Molecular characterization of infectious clones of the minute virus of canines reveals unique features of bocaviruses. Journal of virology, 83(8), 3956-3967. https://10.1128/JVI.02569-08

Wang, E., Liu, W., Yang, B., Liu, J., Ma, X., \& Lan, X. (2014). Complete sequence and phylogenetic analysis of a porcine bocavirus strain swBoV CH437. Virus genes, 48, 387-390. https://10.1007/s11262-013-1032-x

Wang, Y., Zhao, J., Zheng, M., Liu, Z., Yuan, J., Zhao, J., ... Yang, S. (2017). Genome Sequence of a Porcine Bocavirus Detected in Feces of Domestic Minks in China. Genome announcements, 5(45). https://10.1128/genomeA.01170-17

Xiong, Y. Q., You, F. F., Chen, X. J., Chen, Y. X., Wen, Y. Q., \& Chen, Q. (2019). Detection and phylogenetic analysis of porcine bocaviruses carried by murine rodents and house shrews in China. Transboundary and Emerging Diseases, 66:259-267. https://10.1111/tbed.13011

Yang, W. Z., Yu, J. M., Li, J. S., Cheng, W. X., Huang, C. P., \& Duan, Z. J. (2012). Genome characterization of a novel porcine bocavirus. Archives of virology, 157, 2125-2132. https://10.1007/s00705-012-1407-7

Zeng, S., Wang, D., Fang, L., Ma, J., Song, T., Zhang, R., ... Xiao, S. (2011). Complete coding sequences and phylogenetic analysis of porcine bocavirus. Journal of general virology, 92:784-788. https://10.1099/vir.0.028340-0

Zhai, S., Yue, C., Wei, Z., Long, J., Ran, D., Lin, T., \& Yuan, S. (2010). High prevalence of a novel porcine bocavirus in weanling piglets with respiratory tract symptoms in China. Archives of Virology, 155(8), 13131317. https://10.1007/s00705-010-0698-9

Zhang, Q., Hu, R. M., Tang, X. B., Wu, C. L., He, Q. G., Zhao, Z. Q., .. Wu, B. Occurrence and investigation of enteric viral infections in pigs with diarrhea in China, Archives of Virology, 158(2013)1631-1636. https://10.1007/s00705-013-1659-x

Zhang, B., Tang, C., Yue, H., Ren,Y., \& Song, Z. (2014). Viral metagenomics analysis demonstrates the diversity of viral flora in piglet diarrhoeic faeces in China. The Journal of general virology, 95, 1603-1611. https://10.1099/vir.0.063743-0

Zhang, Q., Zhang, C., Gao, M., He, X., Diao, Y., Goyal, S. M., \& Huang, J. (2015). Evolutionary, epidemiological, demographical, and geographical dissection of porcine bocavirus in China and America. Virus Research, 195, 13-24. https://10.1016/j.virusres.2014.09.012

Zhou, F., Sun, H., \& Wang, Y. (2014). Porcine bocavirus: Achievements in the past five years. Viruses, 6(12), 4946-4960. https://10.3390/v6124946

Zhou, Y., Xu, J., Wang, W. L., Song, S. W., Zhu, S. K., Meng, Q. F., .. Luan, W. M. (2018a). A TaqManbased real-time PCR assay for the detection of Ungulate bocaparvovirus 2. Journal of virological methods, 261, 17-21. https://10.1016/j.jviromet.2018.07.013 
Zhou, Y., Xu, J., Zhu, S. K., Meng, Q. F., Lin, Z. X., Chen, R., \& Qian, A. D. (2018b). Genetic analysis of three porcine bocaparvoviruses and identification of a natural recombinant breakpoint in NS1. Archives of Virology, 163:707-712. https://10.1007/s00705-017-3606-8

\section{Figure legends}

Fig.1 Phylogenetic analysis based on the complete genome sequences of two PBoV strains CH/HNZM and PBoV-TY together with 35 reference strains. The tree was generated by the neighbor-joining method in MEGA7 software, and bootstrap values were indicated for each node from 1, 000 replicates. The two PBoV strains from the present study are marked with black solid circles, and the GenBank accession numbers are shown in parentheses.

Fig.2 Determination of potential recombination events by RDP4.39 programs (RDP, GENECONV, BOOTSCAN, MaxChi, Chimaera, SiScan and 3Seq $)(P<0.01)$. One putatively recombinant breakpoint was existed in GD18 (KJ755666) strain that in the VP1/2 gene and located at position 3,458 to 4,986 nt of complete genome. The analysis was performed with an RDP distance model with window size of 20 .

\section{Hosted file}

Table 1 .docx available at https://authorea.com/users/339521/articles/465709-moleculardetection-phylogenetic-and-evolutionary-analysis-of-porcine-bocavirus-in-central-china

\section{Hosted file}

Table 2.doc available at https://authorea.com/users/339521/articles/465709-moleculardetection-phylogenetic-and-evolutionary-analysis-of-porcine-bocavirus-in-central-china 

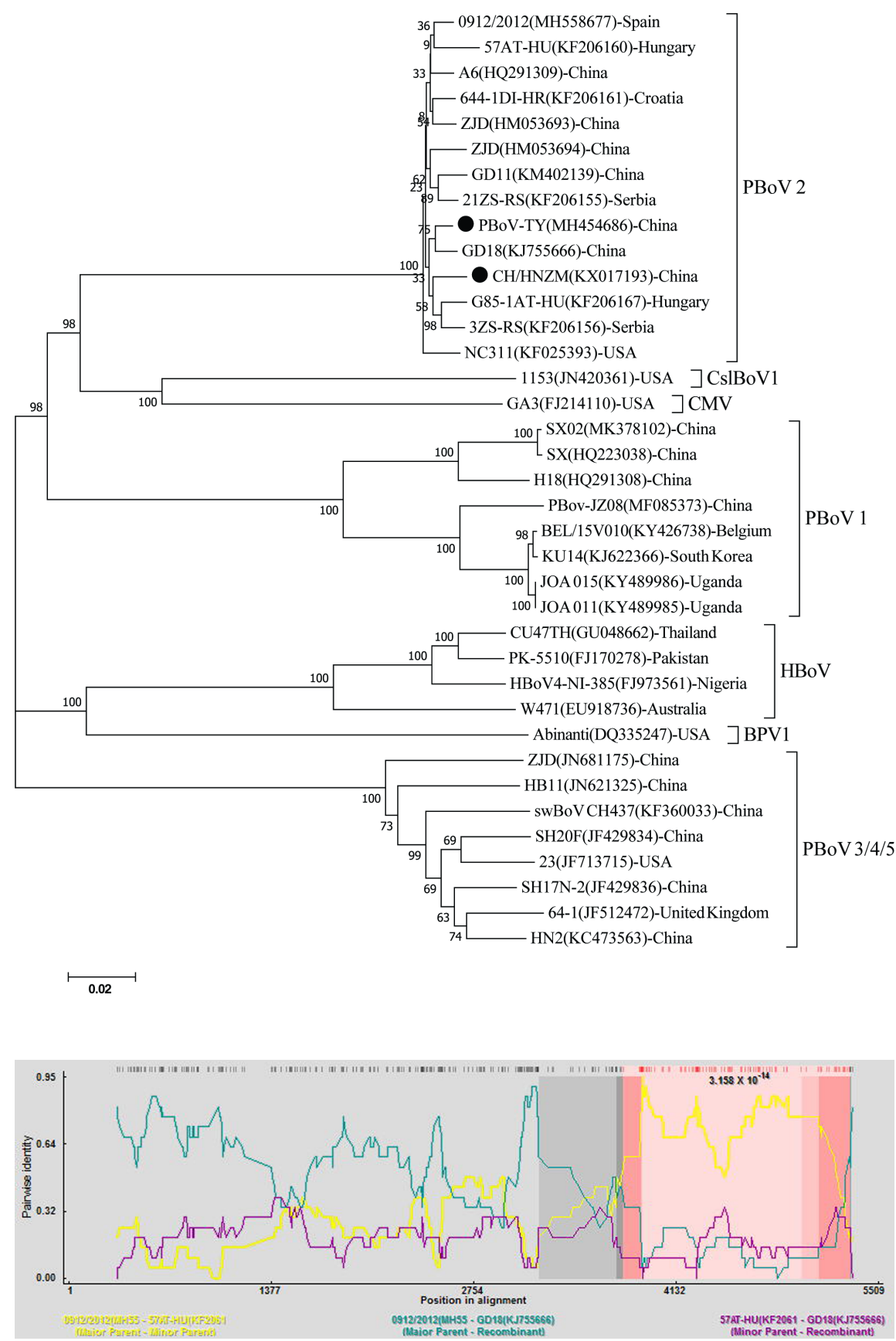